\title{
PENGEMBANGAN APLIKASI KESEHATAN BERBASIS MOBILE UNTUK PEMANTAUAN DETEKSI DINI TUMBUH KEMBANG (DDTK) ANAK USIA 4-6 TAHUN
}

\author{
Untung Nopriansyah ${ }^{1}$, Heny Wulandari ${ }^{2}$, Ratna \\ Pangastuti $^{3}$
}

\author{
${ }^{1}$ Universitas Islam Negeri Raden Intan Lampung, Indonesia \\ ${ }^{2}$ Universitas Islam Negeri Sunan Ampel Surabaya, Indonesia \\ Email: jengheny@yahoo.co.id
}

\begin{abstract}
Growth and development detection activities for children aged 4-6 years is one of the services provided at the Early Childhood Education Unit. The research aims to develop-based health applications mobile for monitoring early detection of child growth and development aged 4-6 years. Using quantitative research methods with a modified $R \& D$ model approach from Borg and Gall, namely 1) preliminary studies, 2) planning, 3) design development, 4) limited field testing, 5) revised limited field test results, 6) wider field tests, 7 ) wider revision of field test results, 8) trials, 9) final products; 10) dissemination and implementation. This research was conducted in kindergarten. The research subjects were kindergarten children aged 4-6 years and teachers [Mal] taken using purposive sampling technique. Data collected through filling in the questionnaire. Data analysis was performed descriptively quantitative. The results of the study of the validation of early childhood education experts state that valid indicators of ease with an average of 3.6, valid on indicators according to grammar with an average of 4 and very valid on indicators according to the characteristics of children aged 4-6 years. The main trial gets $100 \%$ results (5 teachers) means it is proper to use.
\end{abstract}

Keywords: Mobile Based Health Applications, Early Detection.

\begin{abstract}
Abstrak
Kegiatan deteksi tumbuh kembang pada anak usia 4-6 tahun merupakan salah satu layanan yang diberikan pada Satuan Pendidikan Anak Usia Dini. Penelitian bertujuan untuk mengembangkan aplikasi kesehatan berbasis mobile untuk pemantauan deteksi dini tumbuh kembang anak usia 4-6 tahun. Menggunakan metode penelitian kuantitatif dengan pendekatan modifikasi model R\&D dari Borg and Gall yaitu 1) studi pendahuluan, 2) perencanaan, 3) pengembangan desain, 4) uji lapangan terbatas, 5) revisi hasil uji lapangan terbatas, 6) uji lapangan lebih luas, 7) revisi hasil uji lapangan lebih luas, 8) uji coba, 9) produk akhir; 10) diseminasi dan implementasi. Penelitian ini dilakukan di Taman Kanak-Kanak. Subjek penelitian merupakan anak Taman Kanak-kanak usia 4-6 tahun dan guru yang diambil menggunakan teknik purposive sampling. Data dikumpulkan melalui pengisian kuisioner. Analisis data dilakukan secara deskriptif kuantitatif. Hasil penelitian dari validasi ahli pendidikan anak usia dini menyatakan bahwa valid pada indikator kemudahan dengan rata-rata 3,6, valid pada indikator sesuai tata bahasa dengan rata-rata 4 dan sangat valid pada indikator sesuai karakteristik anak usia 4-6 tahun. Uji coba utama mendapatkan hasil $100 \%$ (5 orang guru) artinya layak digunakan.
\end{abstract}

Kata Kunci: Aplikasi Kesehatan Berbasis Mobile, Deteksi Dini. 


\section{PENDAHULUAN}

Tumbuh kembang anak merupakan faktor yang penting. Keberhasilan setiap fase tumbuh kembang ternyata berpengaruh terhadap kemampuan anak di fase selanjutnya (Sulistyawati, 2014). Para ahli keperawatan diantaranya Paplau H mengungkapkan bahwa kesehatan merupakan proses yang berlangsung menuju kepada kretifitas, konstruktif, dan produktif. Dengan demikian bahwa kesehatan adalah suatu hal yangpenting keberadaannya dalam membentuk sumber daya manusia yang unggul. Upaya pemeliharaan kesehatan perlu mendapatkan perlakuan dan perhatian khusus guna menunjang kepentingan pembangunan karakter bangsa (Udu et al., 2019). Hasil Riset Kesehatan Dasar (Riskesdas) 2010 tentang penyebaran status gizi balita pada Provinsi Sulawesi Utara diperoleh data gizi buruk sebesar 4,3\%, gizi kurang 11,5\%, gizi baik 80,7\%, dan gizi lebih 3,6\%.3 ,prevelensi status gizi nasional, prevalensi berat kurang pada tahun 2013 yaitu 19,6\% dimana 5,7\% gizi buruk dan 13,9\% gizi kurang. Data di Sulawesi Utara untuk 2013 menunjukkan prevalensi status gizi BB/TB<-2SD tahun 2013 adalah 10\% (Amirullah et al., 2020). Menurut Soetjiningsih untuk memenuhi kebutuhan gizi anak, dalam memberikan makanan yang tepat pada anak harus dilihat dari berbagai aspek, seperti sosial ekonomi, agama dan budaya, disamping aspek medik dari anak itu sendiri. Makanan pada anak usia dini harus serasi, selaras dan seimbang. Serasi artinya sesuai dengan tingkat tumbuh kembang anak (Laode Anhusadar, 2020). Satu upaya pembinaan tumbuh kembang anak secara komprehensif dan berkualitas yaitu penyelenggaraan kegiatan stimulasi, deteksi, dan intervensi dini tumbuh kembang (SDIDTK) anak. Kegiatan SDIDTK ini dilaksanakan secara menyeluruh dan terkoordinasi serta diselenggarakan dalam bentuk kemitraan antara keluarga, masyarakat dan tenaga profesional serta kebijakan yang berpihak pada pelaksanaan program SDIDTK. Kegiatan deteksi dini tumbuh kembang (DDTK) anak usia 4-6 tahun merupakan serangkaian kegiatan yang terintegrasi dengan PAUD/TK dan kegiatan Posyandu, bahkan saat ini berbagai layanan terintegrasi dalam satu atap, hal ini dikenal dalam konsep PAUD Holistik Integratif (HI). Dalam pelaksanaannya memang tidak semuanya berjalan lancar selalu ada kendala dan hambatan yang dihadapi.

Pertumbuhan dan juga perkembangan merupakan suatu proses alami yang terjadi dalam setiap siklus kehidupan manusia, dimulai sejak anak dalam kandungan sampai akhir hayatnya. Pertumbuhan lebih lebih menitikberatkan pada perubahan secara fisik yang bersifat kuantitatif, sedangkan perkembangan lebih bersifat kualitatif, yang arrtinya pertumbuhan merupakan bserangkaian perubahan progresif sebagai akibat dari proses kematangan dan pengalaman. Usia lahir hingga jenjang pendidikan dasar awal, sering disebut masa keemasan dan juga merupakan 
masa kritis dalam tahapan kehidupan, yang akan mementukan perkembangan anak pada tahap selanjutnya. Masa ini penting karena merupakan masa yang tepat untuk meletakan dasar-dasar pengembangan kemampuan dari perkembangan fisik, bahasa, sosial-emosional, konsep diri, seni, moral dan nilai-nilai agama (Mansur, 2014). Hasil penelitian menyimpulkan bahwa Memahami tumbuh kembang si kecil yang sedang berada pada masa prasekolah sudah pasti tidak memadai hanya dengan membaca tulisan sekecil ini. Studi di jurusan PGRA khususnya, diharapkan dapat mengelaborasi pemahaman kita tentangnya. Namun demikian, pasti pula tidak cukup waktu untuk memahami yang sebenarnya, di samping terjadi karakter variatif tiap anak, juga ilmunya sangat luas. Tulisan ini sekedar stimulan untuk menyadarkan kita bahwa si kecil hakikatnya tidak sekecil seperti yang kita kira. Itulah sebabnya, ada jurusan tersendiri untuk memahami usia prasekolah, salah satunya di PGRA IAIN SNJ Cirebon ini (Eti Nurhayati, 2012).

Agar si anak dapat tumbuh dan berkembang secara optimal, maka orangtua setidaknya harus memenuhi kebutuhan dasar si anak. Kebutuhan dasar anak diantaranya adalah perlindungan dari kekerasan dan kasih sayang, makanan bergizi, perumahan dan lingkungan yang nyaman serta sandang, udara segar dan cukup cahaya matahari, bermain dan istirahat, pencegahan penyakit dan kecelakaan, latihan ketrampilan dan kebiasaan yang diperlukan untuk

kehidupan sehari-hari. Kebutuhan psikis anakdiantaranya adalah nilai-nilai luhur dan keteladanan sebagai manusia, perasaan disayangi dan dicintai, rasa aman karena merasa memiliki orang yang dicintai, merasa memiliki hubungan interpersonal yang kuat dengan keluarga, mengenal lingkungan sekitar, tidak merasa tertekan oleh larangan-larangan, disiplin, rasa tanggung jawab serta kesempatan membantu orang lain, kesempatan untuk meraih sukses dalam bidang yang dikerjakan, kesempatan belajar dari pengalaman yang dilalui, kesempatan terlepas dari ketergantungan orang lain. Peran orangtua diperlukan agar anaknya dapat tumbuh dan berkembang secara optimal. Dapat disimpulkan orangtua harus senantiasa mengawasi dan memperhatikan, dan memberikan fasilitas untuk tumbuh dan berkembang (Aisyah et al., 2014).

Informasi pelaksanaan deteksi dini tumbuh kembang (DDTK) untuk anak usia 4-6 tahun di Indonesia diperoleh berdasarkan studi pendahuluan dan studi literasi. Adapun hasilnya sebagai berikut:

1. Potensi jumlah anak usia dini di Indonesia begitu besar pada tahun 2016 berjumlah 33.563.483 (Kemenkes, 2017) dan tahun 2017 berjumlah 33.496.280 (Kemenkes, 2018), hal ini menjadi perhatian pemerintah untuk memberikan layanan yang optimal. Pemerintah melalui Bapenas merumuskan strategi nasional program PAUD Holistik 
Integratif dengan layanan satu atap harapannya anak usia dini mendapatkan layanan nutrisi, kesehatan, layanan pendidikan, perawatan, dan perlindungan. Pendekatan holistik Integratif memberikan kesempatan anak untuk mengembangkan keterampilan berbahasa, kecerdasan, kepribadian, perilaku sosial, mental, ketahanan psikososial dan prestasi akademik (Wulandari et al., 2018). Selain itu program Bina Keluarga Balita juga memberikan layanan kepada anak dan orang tua dalam tumbuh kembang anak. Keterlibatan orang tua dapat dilihat dari aspek outcome pelaksanaan bina keluarga balita telah memenuhi kriteria, hal ini dapat dilihat dari hasil yang diperolah dari penyelengaraan bina keluarga balita yang yang bisa menghasilkan orang tua yang kreatif, untuk evaluasi outcome dari bina keluarga balita menunjukkan adanya kreatifitas orang tua yaitu orang tua membuat sendiri alat permainan edukatif, orang tua menggunakan media di dalam rumah dan orang tua berhasil dan berprestasi(Islamiyah et al., 2020) Pemberian layanan kesehatan salah satunya melalui layanan stimulasi, deteksi, dan intervensi dini tumbuh kembang (SDIDTK) anak. Adapun data jumlah anak usia dini di Indonesia secara detail data disajikan sebagai berikut:

Tabel 1. Jumlah Anak Usia Dini Di Indonesia

\begin{tabular}{cccc}
\hline No. & Aspek & Tahun 2016 & Tahun 2017 \\
\hline 1 & Jumlah anak usia dini (0-4 tahun) & 23.960 .310 & 23.848 .283 \\
2 & Jumlah anak pra sekolah (5-6 tahun) & 9.603 .173 & 9.647 .997 \\
& Jumlah Total & 33.563 .483 & 33.496 .280
\end{tabular}

2. Pelaksanaan deteksi dini tumbuh kembang (DDTK) masih memliki hambatan antara lain: a) pelaksanaan DDTK di PAUD/TK masih dilakukan secara manual yaitu pengisian menggunakan formulir kertas, b) banyaknya layanan jenis DDTK yang harus diberikan sehingga dalam menganalisis membutuhkan waktu lama, hal ini dirasa kurang efisien jika dihadapkan pada situasi peserta berjumlah banyak, c) proses pemantauan DDTK belum optimal karena data tersimpan secara manual masih dalam bentuk rekapan formulir kertas di setiap PAUD/TK sehingga perlu adanya penguatan sistem informasi penunjang DDTK, d) masih ada PAUD/TK di Indonesia yang belum masuk dalam jaringan pembinaan Puskesmas padahal anak prasekolah seharusnya mendapatkan layanan DDTK.

3. Dibutuhkan inovasi untuk memperkuat sistem informasi pemantauan deteksi dini tumbuh kembang (DDTK) yang lebih efisien. 
Perkembangan inovasi layanan kesehatan di Indonesia maupun Negara lain telah semakin pesat, hal ini dilakukan untuk meningkatkan kualitas layanan dan jangkauan jumlah sasaran. Montana merupakan Negara bagian Amerika Serikat menggunakan teknologi kesehatan berbasis mobile untuk mendukung pemulihan pasien di Pusat Kesehatan Berkualitas Federal (FQHCs) dengan meminimalkan beban pengumpulan data dan pemantauan (Brown, 2015). Selain itu ada juga teknologi kesehatan berbasis smart watches melalui sensor inersia membantu pemantauan penyakit yang mudah diukur seperti gangguan gaya berjalan (King \& Sarrafzadeh, 2018). Penelitian lain tentang teknologi berbasis ponsel memiliki potensi untuk meningkatkan layanan kesehatan primer di Negara berpenghasilan rendah seperti Bangladesh (Uddin et al., 2017), menggunakan teknologi Mobile Continuum Of Care Service (CCS) untuk kesehatan ibu dan anak: strategi penguatan sistem kesehatan di negara berpenghasilan rendah dan menengah (Balakrishnan et al., 2016), paradigma baru teknologi seluler kesehatan mental salah satu alternatif yang menguntungkan untuk mencapai pendekatan yang lebih holistik dan integratif pada praktik klinis di dunia nyata (Hidalgo-Mazzei et al., 2018), monitoring berbasis mobile dari cedera otak traumatis pada orang dewasa tua (Irimia et al., 2017), desain dan evaluasi aplikasi ponsel untuk membantu pemantauan diri dari penyakit ginjal kronis di Negara berkembang hasilnya aplikasi mHealth dirancang untuk membantu diagnosis dini penyakit ginjal kronis dan memonitor mempertimbangkan atribut kualitas seperti keamanan, efektivitas, dan kegunaan. Nilai Kappa global sebesar 0,7119 menunjukkan tingkat substansial kesepakatan (Sobrinho et al., 2018). Di Indonesia pelaksanaan deteksi dini tumbuh kembang (DDTK) sangat penting bahkan menjadi salah satu acuan dalam mengembangkan program fisik-motorik. Program aktivitas fisik bertujuan mengembangkan kematangan kinestetik melalui bermain dan membutuhkan bimbingan guru (Taroreh \& Wijaya, 2020). Pada level satuan pendidikan selanjutnya yaitu di sekolah dasar program aktivitas fisik dapat dikembangkan menggunakan permainan tradisional namun pemetaan geraknya harus jelas (Taroreh \& Satria, 2020)

Pengembangan aplikasi kesehatan berbasis mobile untuk pemantauan deteksi dini tumbuh kembang (DDTK) anak usia 4-6 tahun melalui penelitian ini digunakan untuk mengatasi permasalahan PAUD/TK di Indonesia. Pendidikan di PAUD/TK memiliki peran yang penting karena diselenggarakan sebagai upaya untuk membantu meletakkan dasar-dasar pengembangan pada semua aspek dan merupakan usia yang sensitif (Taroreh, 2017). Adapun matrik pemantauan Deteksi Dini Tumbuh Kembang (DDTK) Anak Usia 4-6 tahun sebagai berikut: 
Tabel 2. Matrik Keterbaharuan Pemantauan Deteksi Dini Tumbuh Kembang (DDTK) Anak Usia 4-6 tahun

\begin{tabular}{|c|c|c|}
\hline Aspek & $\begin{array}{c}\text { Pemantauan Deteksi Dini } \\
\text { Tumbuh Kembang (DDTK) } \\
\text { Anak Usia 4-6 Tahun Yang } \\
\text { Lama }\end{array}$ & $\begin{array}{c}\text { Pemantauan Deteksi Dini Tumbuh } \\
\text { Kembang (DDTK) } \\
\text { Anak Usia 4-6 Tahun Yang } \\
\text { Dikembangkan }\end{array}$ \\
\hline Logistik & $\begin{array}{l}\text { Menggunakan formulir } \\
\text { deteksi dini tumbuh kembang } \\
\text { (DDTK) }\end{array}$ & $\begin{array}{c}\text { Menggunakan aplikasi kesehatan } \\
\text { berbasis mobile untuk pemantauan } \\
\text { deteksi dini tumbuh kembang (DDTK) } \\
\text { Anak usia 4-6 tahun }\end{array}$ \\
\hline $\begin{array}{c}\text { Biaya } \\
\text { operasional }\end{array}$ & $\begin{array}{l}\text { Menggunakan dana untuk } \\
\text { penggandaan formulir deteksi } \\
\text { dini tumbuh kembang } \\
\text { (DDTK) }\end{array}$ & Gratis \\
\hline $\begin{array}{c}\text { Waktu } \\
\text { Analisis }\end{array}$ & Lebih lama & Lebih cepat dan efisien \\
\hline $\begin{array}{c}\text { Grafik } \\
\text { analisis }\end{array}$ & Tidak ada & Humanis dengan emot lucu \\
\hline $\begin{array}{c}\text { Keamanan } \\
\text { data }\end{array}$ & Mudah hilang, rusak & Aman tersimpan dalam data base google \\
\hline
\end{tabular}

Berdasarkan hasil analisis kebutuhan (need assesment) tersebut maka penelitian ini akan mengembangkan aplikasi kesehatan berbasis mobile untuk pemantauan deteksi dini tumbuh kembang (DDTK) anak usia 4-6 tahun. Penelitian sebelumnya tentang aplikasi tumbuh kembang dapat dilihat dari hasil penelitian yang menyimpulkan bahwa aplikasi dari tes Denver II ini dapat membantu kinerja tim kesehatan dalam mengelola data pasien dan pelaksanaan tes Denver II, hingga memudahkan tenaga kesehatan profesional melakukan pengujian tes Denver II. Setelah dilaksanakan pengujian keakuratan, dapat diambil kesimpulkan bahwa sistem berbantu komputer berjalan dengan baik, sehingga hasil output dari sistem memiliki tingkat keakuratan yang tinggi dengan pengujian menggunakan manual tes Denver II. Untuk penelitian selanjutnya, kedepannya pada halaman cetak hasil dapat menambahkan form komentar pada halaman nilai dan halaman hasil, agar pengguna dapat dengan mudah memberikan sedikit ulasan terkait hasil pelaksaan tes Denver II yang telah dilakukan sehingga dapat memberikan tampilan yang lebih informatif kepada pengguna, berikutnya dapat menyesuaikan lebih baik dengan tes manual sehingga mampu mengurangi tingkat human error(Ivantoni \& Muhimmah, 2015). Hasil penelitian lain menyimpulkan bahwa Dari analisa uji coba penelitian, dapat ditarik kesimpulan sebagai berikut: (1) Aplikasi ini dapat melakukan deteksi dini tumbuh kembang anak dari usia nol hingga 72 bulan dengan menggunakan tinggi/panjang badan, berat badan dan lingkar kepala sebagai data pertumbuhan anak, serta Kuisioner Pra Skrinning Perkembangan (KPSP) sebagai data perkembangan anak. (2) Aplikasi ini juga dapat mendeteksi gangguan 
tumbuh kembang anak yang didapat dari masukan pengguna menggunakan instrument KPSP, dengan cara menghitung jumlah jawaban dari pengguna aplikasi mengenai tumbuh kembang anak. (3) Terdapat tiga hasil uji coba aplikasi yang telah dilakukan oleh ahli tumbuh kembang anak $(81 \%)$, oleh tim medis kesehatan $(89 \%)$, serta oleh orang tua $(81 \%)$, dimana ketiga kelompok tersebut dapat disimpulkan bahwa aplikasi dapat dikategorikan sebagai alat bantu yang sangat efektif dan bisa digunakan bagi orang tua dalam mendeteksi dini tumbuh kembang anak (Saurina, 2016).

\section{METODE PENELITIAN}

Metode penelitian menggunakan metode kuantitatif dengan pendekatan modifikasi model R\&D dari Borg \& Gall yang terdiri dari sepuluh langkah yaitu (Borg \& Gall, 2007).

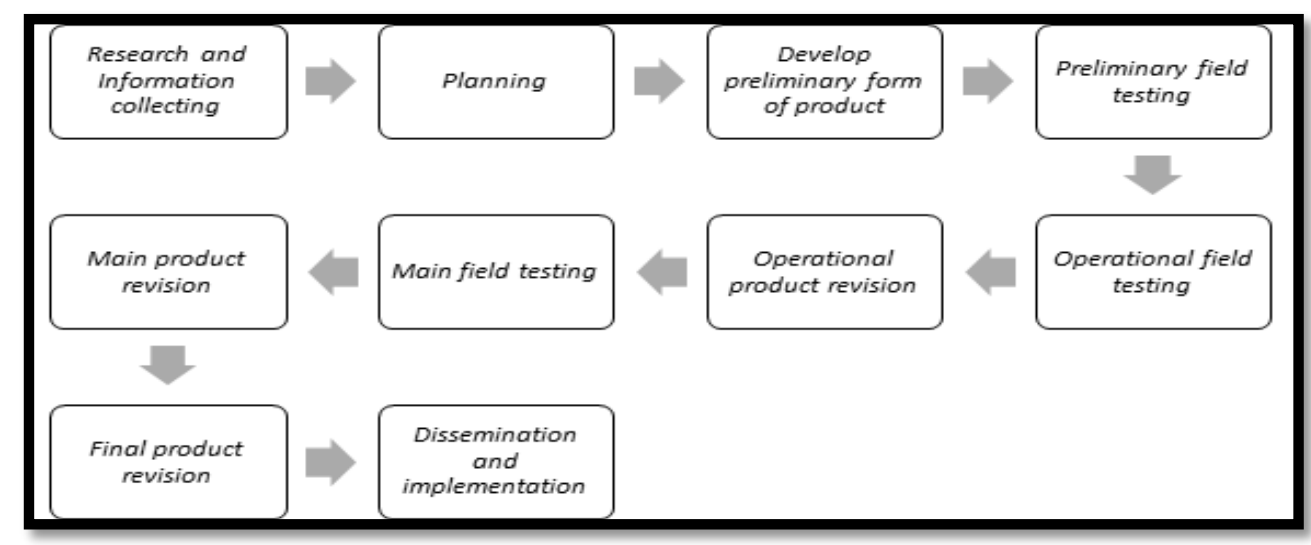

Gambar 1. Rancangan Metode Penelitian Pengembangan

Uraian dari sepuluh langkah pengembangan diatas sebagai berikut: 1) studi pendahuluan Pada tahap ini menitik beratkan untuk mengetahui analisis kebutuhan. Fokusnya yaitu a) mengidentifikasi pelaksanaan pemantauan deteksi dini tumbuh kembang (DDTK) untuk anak usia 4-6 tahun di PAUD/TK, b) menganalisis karakteristik anak usia 4-6 tahun, c) melakukan studi literatur mengenai penggunaan aplikasi kesehatan berbasis mobile; 2) perencanaan (planning); 3) pengembangan desain (develop preminary from of product) langkah ini meliputi: a) menentukan desain produk yang akan dikembangkan yaitu aplikasi kesehatan berbasis mobile untuk pemantauan deteksi dini tumbuh kembang (DDTK) anak usia 4-6 tahun, b) penyiapan materi berupa deteksi dini tumbuh kembang (DDTK), c) menyusun buku petunjuk penggunaan; 4) uji lapangan terbatas (preliminary field testing), pada tahap ini menggunakan 30 anak usia dini dan 3 guru PAUD. Selain itu juga melakukan focus group discution (FGD) yang dihadiri oleh ahli dan stakeholder pengguna; 5) revisi hasil uji lapangan terbatas (main product revision), langkah ini merupakan perbaikan model berdasarkan uji lapangan terbatas; 
6) uji lapangan lebih luas (main field test), langkah ini mengujikan produk yang dikembangkan dalam skala yang lebih besar. pada tahap ini menggunakan 150 anak usia dini dan 3 guru paud; 7) revisi hasil uji lapangan lebih luas (operational product revision), langkah ini merupakan tahap perbaikan. penyempurnaan produk dari hasil uji lapangan lebih luas ini akan lebih memantapkan produk yang kita kembangkan; 8) uji coba utama (operational field testing) yaitu langkah uji validasi terhadap model operasional yang telah dihasilkan. pada tahap ini menggunakan 50 anak usia dini dan 5 guru paud. tujuan langkah ini adalah untuk menentukan efektifitas suatu model yang dikembangkan benar-benar siap dipakai di paud; 9) produk akhir; 10) diseminasi dan implementasi, langkah menyebarluaskan produk/model yang dikembangkan kepada khalayak/masyarakat luas.

Teknik pengumpulam data dalam penelitian ini menggunakan kuiseioner. Kuiseioner digunakan sebagai instrumen untuk uji validasi produk oleh ahli serta uji kelompok kecil dan uji kelompok besar untuk mengumpulkan pendapat guru. Analisis data dilakukan secara deskriptif kuantitatif. Data kuantitatif diperoleh dari hasil validasi ahli pendidikan anak usia dini berdasarkan skala Likert (interval 1-5) seperti pada tabel berikut:

Tabel 3. Skor Validasi Ahli Produk

\begin{tabular}{cc}
\hline Skor & Kriteria \\
\hline 5 & Sangat Setuju \\
4 & Setuju \\
3 & Cukup Setuju \\
2 & Kurang Setuju \\
1 & Sangat Kurang Setuju \\
\hline
\end{tabular}

Hasil kuesioner kemudian dianalisis berikut ini:

a. Mencari rata-rata perolehan skor setiap indikator dengan

rumus: $\bar{x}=\frac{\sum_{i=1}^{n} x_{i}}{n}$

Keterangan:

$\bar{x}=$ rata-rata skor

$x_{i}=$ skor ke $-\mathrm{i}$

$n=$ banyaknya keterangan pertanyaan

b. Skor rata-rata tersebut kemudian dikonversikan menjadi data kualitatif berdasarkan kriteria penilaian skala 5 . 
Tabel 4. Pedoman Konversi Skor Kualitatif

\begin{tabular}{cc}
\hline Interval & Kriteria \\
\hline $\bar{x}>\bar{x}_{i}+1,8 S b_{i}$ & Sangat Baik \\
$\mathrm{X}_{i}+0,6 S b_{i}<\bar{x} \leq^{-} \mathrm{x}+1,8 S b_{i}$ & Baik \\
$\mathrm{X}_{i}-0,6 S b_{i}<\bar{x} \leq^{-}+0,6 S b_{i}$ & Cukup Baik \\
$\mathrm{X}_{i}-1,8 S b_{i}<\bar{x} \leq^{-}-0,6 S b_{i}$ & Kurang Baik \\
$\bar{x} \leq^{-} \mathrm{x}-1,8 S b_{i}$ & Sangat Kurang \\
\end{tabular}

Berdasarkan tabel 4 hasil validasi ahli dikategorikan menjadi tabel 5 yaitu:

Tabel 5. Interval Kriteria Validasi Ahli

\begin{tabular}{ccl}
\hline Rentang Skor & Kriteria & \multicolumn{1}{c}{ Kevalidan } \\
\hline $\bar{x}>4,2$ & Sangat Baik & Sangat Valid \\
$3,4<\bar{x} \leq 4,2$ & Baik & Valid \\
$2,6<\bar{x} \leq 3,4$ & Cukup Baik & Cukup Valid \\
$1,8<\bar{x} \leq 2,6$ & Kurang Baik & Kurang Valid \\
$\bar{x} \leq 1,8$ & Sangat Kurang & Sangat Kurang Valid \\
& & \\
\hline
\end{tabular}

Kuisioner guru pada uji coba skala kecil dan uji coba skala besar bertujuan untuk mengetahui kelayakan produk. Kuisioner menggunakan skala Guttman dengan dua pilihan jawaban layak atau tidak layak dengan kriteria penilaian sebagai berikut:

Tabel 6. Interprestasi Kelayakan

\begin{tabular}{|c|c|c|}
\hline $\begin{array}{c}\text { Rentang } \\
\text { Persentase }(\%)\end{array}$ & Kriteria & Interprestasi \\
\hline & & Ahli dan guru PAUD/TK menyatakan bahwa aplikasi \\
\hline $50,1 \%-100 \%$ & Layak & $\begin{array}{l}\text { kesehatan berbasis mobile untuk pemantauan deteksi } \\
\text { dini tumbuh kembang (DDTK) anak usia 4-6 tahun } \\
\text { layak digunakan. }\end{array}$ \\
\hline & & Ahli dan guru PAUD/TK menyatakan bahwa aplikasi \\
\hline $0 \%-50 \%$ & Tidak Layak & $\begin{array}{l}\text { kesehatan berbasis mobile untuk pemantauan deteksi } \\
\text { dini tumbuh kembang (DDTK) anak usia 4-6 tahun } \\
\text { tidak layak digunakan. }\end{array}$ \\
\hline
\end{tabular}




\section{HASIL PENELITIAN DAN PEMBAHASAN}

Hasil penelitian menunjukkan bahwa aplikasi kesehatan berbasis mobile untuk pemantauan deteksi dini tumbuh kembang (DDTK) anak usia 4-6 tahun telah dinyatakan valid oleh ahli pendidikan anak usia dini dan layak digunakan berdasarkan hasil uji coba skala kecil, uji coba skala besar dan uji coba utama. Secara rinci dijabarkan sebagai berikut:

1) Tahap pengembangan desain

Tahap ini dilakukan setelah tahap studi pendahuluan dan perencanaan selesai. Di dalam mengembangkan desain terdapat proses validasi ahli yang dilakukan ke ahli pendidikan anak usia dini 2 orang dan 1 praktisi kemudian dilanjutkan dengan Focus Group Discussion (FGD) dengan berbagai stakeholders terkait. Hal ini dilakukan untuk mendapatkan konsesus bersama atau kesepakatan bersama. Adapun hasilnya sebagai berikut:

Tabel 7. Hasil Validasi Ahli

\begin{tabular}{|c|c|c|c|c|c|}
\hline Indikator & $\begin{array}{l}\text { Skor Yang } \\
\text { Diperoleh }\end{array}$ & $\begin{array}{l}\text { Jumlah Ahli } \\
\text { dan Praktisi }\end{array}$ & $\begin{array}{l}\text { Rata- } \\
\text { rata }\end{array}$ & Kriteria & Keterangan \\
\hline Kemudahan & 11 & 3 & 3.6 & Baik & Valid \\
\hline Sesuai Tata Bahasa & 12 & 3 & 4 & Baik & Valid \\
\hline $\begin{array}{l}\text { Sesuai karakteristik } \\
\text { anak usia 4-6 tahun }\end{array}$ & 13 & 3 & 4.3 & Sangat Baik & Sangat Valid \\
\hline
\end{tabular}

Selain hasil validasi ahli juga mendapatkan data kualitatif berupa saran dan masukan ahli, terangkum sebagai berikut:

Tabel 8. Rangkuman Hasil Validasi Ahli

\begin{tabular}{cl}
\hline No. & \multicolumn{1}{c}{ Saran dan Masukan } \\
\hline 1 & Hasil output dari aplikasi ini harapannya akan dijadikan laporan oleh sekolah \\
2 & Rancangan dari draf awal merupakan panduan yang lama sehingga perlu diperbaiki \\
& menggunakan panduan yang baru yaitu standar antropometri yang dikonfirmasi dengan \\
& status gizi sehingga pertumbuhan dikonfirmasi dengan 4 kategori yang baru yaitu 1) \\
& berat badan menurut umur, 2) panjang badan menurut umur, 3) berat badan menurut \\
& panjang badan, 4) indeks masa tubuh menurut umur dan umurnya cukup pada usia 4-5 \\
& tahun sesuai panduan baru (standar antropometri dari Keputusan Menteri Kesehatan RI \\
& No. 1995/Menkes/SK/XII/2010 dan WHO 2005) \\
& Aplikasi digunakan sekolah dari awal 1 tahun pelajaran \\
\hline
\end{tabular}


$4 \quad$ PAUD diukur setiap 6 bulan sekali dengan pertimbangan Berat Badan diukur setiap bulan sedangkan Tinggi Badan diukur setiap 3 atau 6 bulan sekali

5 Aplikasi yang dikembangkan lebih fokus pada pertumbuhan dan perkembangan anak, jika terdapat indikatornya deteksi dini penyimpangan emosional, detieksi gangguan pemusatan perhatian dan hiperaktif terlalu luas sehingga butuh analisis ahli psikologi

6 Aplikasi yang akan dikembangkan sebaiknya simpel dan mudah digunakan dan dilengkapi pedoman penggunaan

7 Aplikasi awal yang sdh dikembangkan belum layak untuk digunakan.

Berdasarkan hasil validasi ahli maka dilakukan revisi sebagai berikut:

Tabel 9. Revisi Model

\begin{tabular}{|c|c|c|}
\hline No. & Perubahan Konsep Model & Perubahan \\
\hline \multirow[t]{7}{*}{1} & Prototipe I (Awal): & Prototipe II (Akhir): \\
\hline & Pengembangan Aplikasi Kesehatan Berbasis & Pengembangan Aplikasi Kesehatan Berbasis \\
\hline & Mobile Untuk Pemantauan Deteksi Dini & Mobile Untuk Pemantauan Deteksi Dini \\
\hline & Tumbuh Kembang (DDTK) anak usia 4-6 & Tumbuh Kembang (DDTK) anak usia 4-6 \\
\hline & Tahun dikembangkan berdasarkan Buku & Tahun dikembangkan \\
\hline & Deteksi Dini Tumbuh Kembang (DDTK) & Keputusan Menteri Kesehatan RI No. \\
\hline & & 1995/Menkes/SK/XII/2010 dan WHO 2005 \\
\hline
\end{tabular}

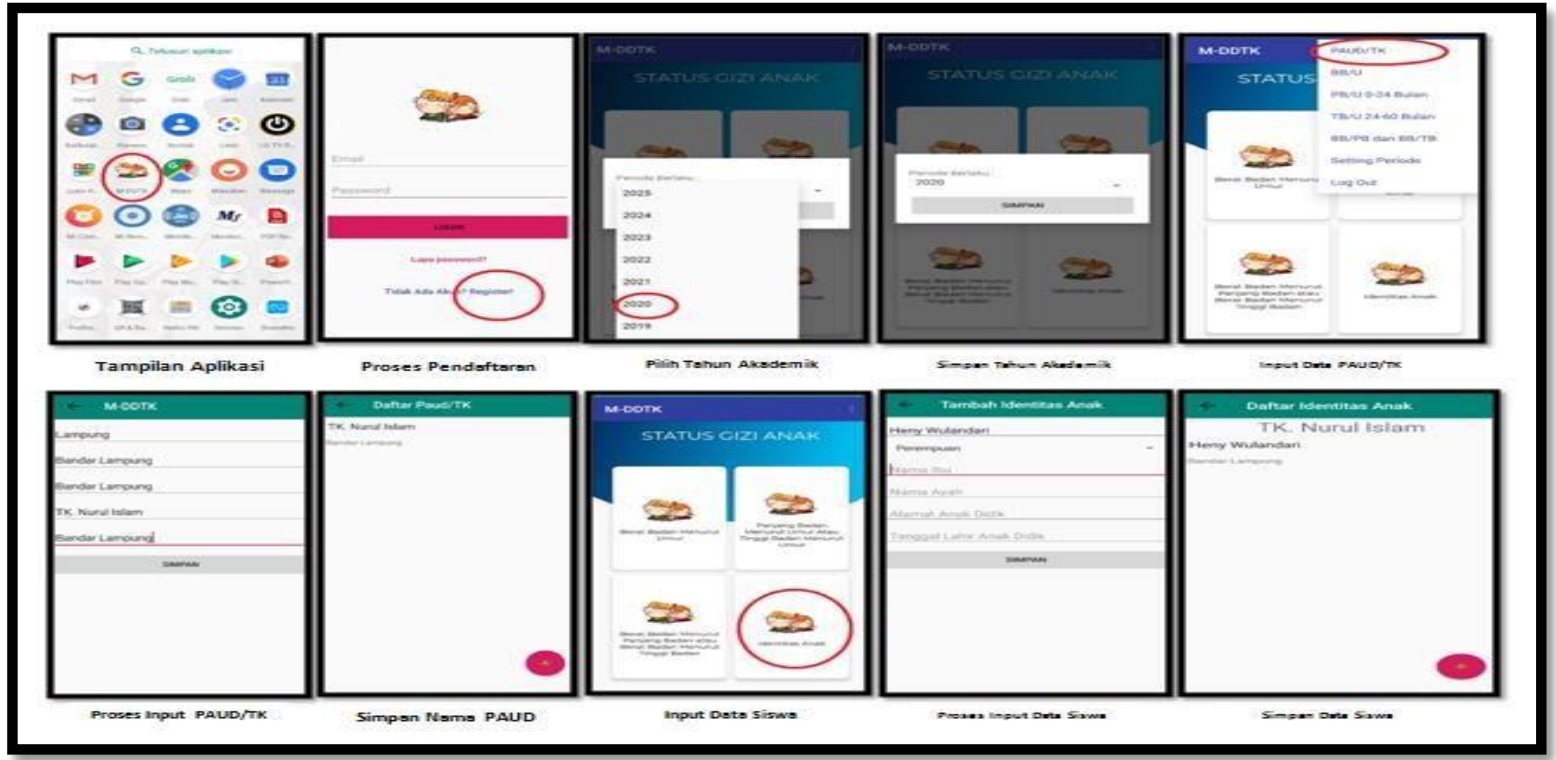




\section{Gambar 2. Proses Tampilan Aplikasi, Regristrasi dan Input Data PAUD/TK, Siswa}

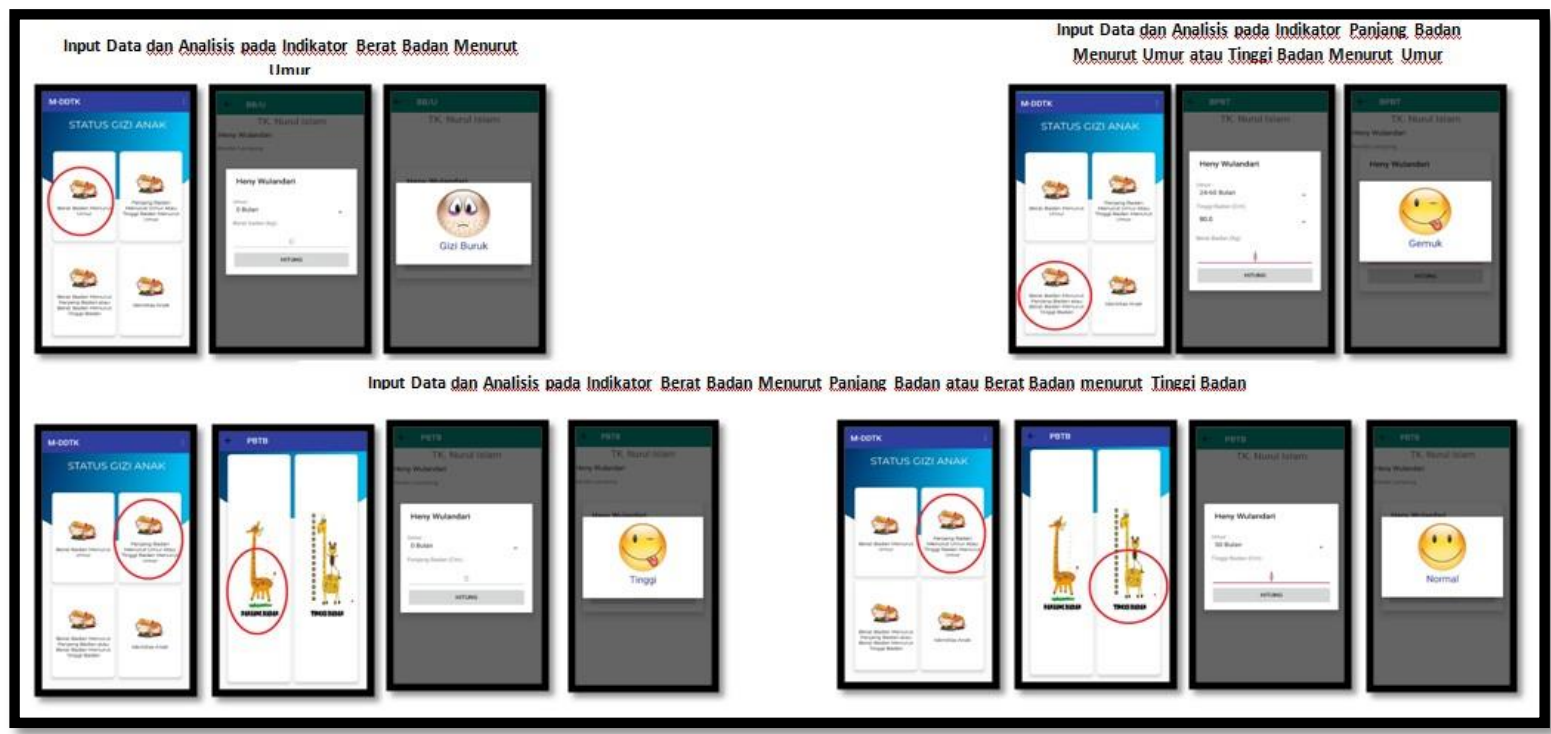

Gambar 3. Proses Input Data dan Analisis Pada Setiap Indikator

2) Tahap uji coba

Tahap ini bertujuan untuk mengetahui kelayakan produk yang dikembangkan. Secara detail dijabarkan sebagai berikut:

Tabel 10. Hasil Uji Coba

\begin{tabular}{|c|c|c|c|c|c|c|c|}
\hline \multirow{3}{*}{ No. } & \multirow{3}{*}{ Uji Lapangan } & \multicolumn{6}{|c|}{ Pendapat Guru } \\
\hline & & \multicolumn{3}{|c|}{ Dapat digunakan } & \multicolumn{3}{|c|}{ Tidak dapat Digunakan } \\
\hline & & (f) & $(\%)$ & Kriteria & (f) & $(\%)$ & Kriteria \\
\hline 1 & Uji Lapangan Terbatas & 3 & 100 & Layak & - & - & - \\
\hline 2 & Uji Lapangan Lebih Luas & 3 & 100 & Layak & - & - & - \\
\hline 3 & Uji Coba Utama & 5 & 100 & Layak & - & - & - \\
\hline
\end{tabular}

Berdasarkan tabel 10 maka aplikasi kesehatan berbasis mobile untuk pemantauan deteksi dini tumbuh kembang anak usia 4-6 tahun yang layak digunakan.

\section{SIMPULAN DAN SARAN}

Penelitian ini telah menghasilkan aplikasi kesehatan berbasis mobile untuk pemantauan deteksi dini tumbuh kembang anak usia 4-6 tahun dan efektif digunakan. Aplikasi ini merupakan salah satu aplikasi alternatif yang dapat digunakan oleh guru, orang tua dan masyarakat dalam memantau deteksi dini tumbuh kembang anak. Bagi penelitian lain yang berminat melakukan penelitian yang sejenis disarankan 1) menggunakan sampel anak usia dini 4-6 tahun dan guru yang lebih banyak, 2) dibutuhkan aplikasi dengan berbagai variabel lain 
yang terintegrasi dan berkaitan dengan deteksi dini tumbuh kembang, 3) pengembangan aplikasi lebih komplek dan detail misalnya menggunakan pendekatan big data.

\section{DAFTAR PUSTAKA}

Aisyah, Siti, A., Mukti, C., Titi, N., \& Dian. (2014). Perkembangan dan konsep dasar pengembangan anak usia dini. Universitas Terbuka.

Amirullah, A., Try, A., Putra, A., Daud, A., \& Kahar, A. (2020). Deskripsi Status Gizi Anak Usia 3 Sampai 5 Tahun Pada Masa Covid 19. 1(2), 16-27. https://doi.org/doi.org/10.37985/murhum.v1i1.3

Balakrishnan, R., Gopichandran, V., Chaturvedi, S., Chatterjee, R., Mahapatra, T., \& Chaudhuri, I. (2016). Continuum of Care Services for Maternal and Child Health using mobile technology - a health system strengthening strategy in low and middle income countries. BMC Medical Informatics and Decision Making, 16(1), 84. https://doi.org/10.1186/s12911-016-0326-z

Borg, W. R., \& Gall, M. (2007). Education Research: An Introduction (4th Edition). In Longman publisher.

Brown, R. (2015). Early findings from a project aimed at implementing mobile health technology for addiction in primary care. Addiction Science \& Clinical Practice, 10(S1), A5. https://doi.org/10.1186/1940-0640-10-S1-A5

Eti Nurhayati. (2012). Memahami Tumbuh Kembang Anak Usia Dini. Society, 1-14.

Hidalgo-Mazzei, D., Young, A. H., Vieta, E., \& Colom, F. (2018). Behavioural biomarkers and mobile mental health: a new paradigm. International Journal of Bipolar Disorders, 6(1), 9. https://doi.org/10.1186/s40345-018-0119-7

Irimia, A., Wei, S., Lu, N., Moore, C. M., \& Kennedy, D. N. (2017). Mobile Monitoring of Traumatic Brain Injury in Older Adults: Challenges and Opportunities. Neuroinformatics, 15(3), 227-230. https://doi.org/10.1007/s12021-017-9335-z

Islamiyah, I., Awad, F. B., \& Anhusadar, L. (2020). Outcome Program Bina Keluarga Balita (BKB): Konseling Orang Tua Dalam Tumbuh Kembang Anak Usia Dini. Zawiyah: Jurnal Pemikiran Islam, 6(1), 41-58. https://doi.org/dx.doi.org/10.31332/zjpi.v6i1.1797

Ivantoni, R., \& Muhimmah, I. (2015). Aplikasi Penentuan Tingkat Tumbuh Kembang Anak Menggunakan Tes Denver II. Seminar Nasional Informatika Medis (SNIMed), 6, 124132.

Kemenkes, R. I. (2017). Data dan informasi profil kesehatan indonesia. Jakarta: Kemenkes $R I$.

Kemenkes, R. I. (2018). Data Dan Informasi Profil Kesehatan Indonesia Tahun 2016. Jakarta, Indonesia.

King, C. E., \& Sarrafzadeh, M. (2018). A Survey of Smartwatches in Remote Health Monitoring. Journal of Healthcare Informatics Research, 2(1-2), 1-24. https://doi.org/10.1007/s41666-017-0012-7

Laode Anhusadar, I. (2020). Penerapan Perilaku Hidup Bersih dan Sehat Anak Usia Dini di Tengah Pandemi Covid 19. Jurnal Obsesi: Jurnal Pendidikan Anak Usia Dini, 5(1), 463-475. https://doi.org/10.31004/obsesi.v5i1.555

Mansur. (2014). Pendidikan Anak Usia Dini dalam Islam. Pustaka Pelajar.

Saurina, N. (2016). Aplikasi Deteksi Dini Tumbuh Kembang Anak Usia Nol Hingga Enam Tahun Berbasis Android. Jurnal Buana Informatika, 7(1), 65-74. https://doi.org/10.24002/jbi.v7i1.485

Sobrinho, A., da Silva, L. D., Perkusich, A., Pinheiro, M. E., \& Cunha, P. (2018). Design and 
evaluation of a mobile application to assist the self-monitoring of the chronic kidney disease in developing countries. BMC Medical Informatics and Decision Making, 18(1), 7. https://doi.org/10.1186/s12911-018-0587-9

Sulistyawati, A. (2014). Deteksi tumbuh kembang anak. Jakarta: Salemba Medika.

Taroreh, B. S. (2017). Development Model Approach Through Exercise Kinesthetic Game Circuit For Children Ages 4-6 Years. JIPES - JOURNAL OF INDONESIAN PHYSICAL EDUCATION AND SPORT, 3(1), 41. https://doi.org/10.21009/JIPES.031.06

Taroreh, B. S., \& Satria, M. H. (2020). Implementasi Permainan Cba Pada Pembelajaran Atletik Sebagai Solusi Alternatif Melestarikan Permainan Tradisional Di Sumatera Selatan. JURNAL CURERE, 4(1), 9-16. https://doi.org/10.36764/jc.v4i1.348

Taroreh, B. S., \& Wijaya, M. A. (2020). Program Aktivitas Fisik Manipulatif Berbasis Kinestetik Untuk Anak Usia 6 Tahun. JURNAL PENJAKORA, 7(1), 1-10. https://doi.org/10.23887/penjakora.v7i1.24258

Uddin, J., Biswas, T., Adhikary, G., Ali, W., Alam, N., Palit, R., Uddin, N., Uddin, A., Khatun, F., \& Bhuiya, A. (2017). Impact of mobile phone-based technology to improve health, population and nutrition services in Rural Bangladesh: a study protocol. $B M C$ Medical Informatics and Decision Making, 17(1), 101. https://doi.org/10.1186/s12911017-0502-9

Udu, S., Anhusadar, L. O., Alias, A., \& Ali, L. (2019). HEDOLE DOLE : STUNTING TRADISIONAL MASYARAKAT WAKATOBI. Al-Izzah: Jurnal Hasil-Hasil Penelitian, 14(2), 32. https://doi.org/10.31332/ai.v14i2.1508

Wulandari, H., Supriyati, Y., \& Jalal, F. (2018). Evaluation of Holistic Integrative Program in Early Childhood Education and Development (PAUD HI). Int. J. of Multidisciplinary and Current Research, 6. https://doi.org/10.14741/ijmcr/v.6.3.2 